\title{
Jogo pedagógico: uma ferramenta de dinamização para o ensino?
}

\author{
Christiane Leal Corrêa (UERJ) \\ Vanessa Valentin Da Costa (Unversidade Gama Filho) \\ Christina Thereza Bassani Teixeira (FAMATHMT) \\ Renato Gonçalves Furtado (Universidade Santa Úrsula)
}

\section{Resumo}

O desenvolvimento de metodologias inovadoras pode contribuir para minimizar os desafios encontrados atualmente na relação ensino-aprendizagem. A realização de oficina com jogo pedagógico pode ser uma útil ferramenta. Objetivou-se, neste estudo, verificar se a oficina de jogo pedagógico contribuiu como motivador na aquisição de conteúdos sobre educação ambiental e sustentabilidade. Turmas do ensino médio (duas do primeiro ano e duas do terceiro) de um colégio particular no município do Rio de Janeiro foram avaliadas. A metodologia foi considerada eficiente, pelos alunos, para relembrar o conteúdo em $98 \%$ dos alunos do $1^{\circ}$ ano e $67 \%$ dos alunos do $3^{\circ}$ ano; para auxiliar na redução da ansiedade por $81 \%$ dos alunos do $1^{\circ}$ ano e $70 \%$ dos alunos do $3^{\circ}$ ano e para melhoria da nota em $98 \%$ dos alunos do $1^{\circ}$ ano e $90 \%$ dos alunos do $3^{\circ}$ ano. Concluímos que a utilização de jogos pedagógicos pode contribuir para aprimorar o trabalho docente e a motivação no aprendizado do discente.

Palavras-chave: Ensino Médio; Jogo Pedagógico; Motivação; Educação Ambiental.

\begin{abstract}
The development of innovative methodologies can contribute to minimize the challenges currently encountered in the relation between teaching and learning. The realization of a workshop with pedagogic games can be a useful tool. The objective of this study was to verify if the pedagogical game workshop contributed as a motivator in the acquisition of contents on environmental education and sustainability. Two classes of the first year of high school and two of the third year of high school of a private college in the city of Rio de Janeiro were evaluated. The methodology was considered efficient by the students to recall the contents in 98\% of the 1st year students and $67 \%$ of the $3 r$ year students, to help reduce anxiety by $81 \%$ of the first year students and $70 \%$ of the students in the first year. 3rd year and for improvement of the grade in $98 \%$ of the students of the 1 st year and $90 \%$ of the students of the 3rd year. We conclude that the use of pedagogical games can contribute to improve the teaching work and motivation in student learning.
\end{abstract}

Keywords: High School; Game Pedagogy; Motivation; Environmental Education; Sustainability.

\section{Introdução}

A dinâmica do aprendizado requer motivação para a aquisição do conhecimento trabalhado. As rápidas mudanças no mundo moderno e a cultura do descartável, que tem a possibilidade de promover uma percepção apenas superficial dos processos envolvidos, fazem com que o aluno possa apresentar dificuldades em manter a atenção em sala de aula.

As características próprias de um jogo pedagógico (dinâmico, motivador e lúdico) podem contribuir para o envolvimento dos sentimentos, emoções e do raciocínio lógico, favorecendo a aprendizagem (KERFOOT; BAKER, 2012). Menegheti e Bueno (2010) descrevem os jogos pedagógicos como valiosas ferramentas que auxiliam em mudanças conceituais, pois possibilitam a abertura para novas perspectivas, facilitam o entendimento do abstrato e incentivam os alunos com uma função motivacional e ainda encorajam o professor a 
levar em consideração o conhecimento anterior dos alunos.

A atual situação da educação no país, como superlotação das salas de aulas, falta de recursos, desvalorização do profissional e a precária estrutura física e metodológica provocam questionamentos aos educadores, de como é possível inovar e transformar o método de ensinar numa experiência motivadora (LIMA; VASCONCELOS, 2006).

É fato que o uso de novas metodologias no processo educacional vem permitindo uma evolução em relação à forma de se construir o conhecimento, possibilitando assim a prática de uma abordagem diferenciada dos métodos tradicionais de ensino-aprendizagem, visando aumentar a motivação e o interesse do aluno para com os conteúdos educacionais. Nesse cenário, o desenvolvimento de metodologias inovadoras é uma forma de minimizar os desafios encontrados, e a proposta de um jogo pedagógico pode ser uma útil ferramenta, visando estratégias diferentes de aprendizagem.

Este trabalho buscou testar a aplicabilidade de um jogo pedagógico J3 A@(Registro 750347, ago/09), como motivador na aquisição de conteúdos relacionados com educação ambiental e sustentabilidade. Para tal proposta, tivemos como objetivos específicos: realizar diagnóstico sobre questões relacionadas com meio ambiente; avaliar a aplicabilidade do jogo pedagógico J3 A@ na aquisição dos conteúdos em educação ambiental e sustentabilidade e mensurar a reação dos alunos perante a ação realizada.

\section{Abordagem metodológica}

O presente trabalho foi aprovado pelo Comitê de Ética em Pesquisa com Seres Humanos da Universidade Veiga de Almeida com o número 0075.0.312.000-15.

O estudo foi realizado com turmas do ensino médio (duas do primeiro ano e duas do terceiro) do Colégio Boas Novas, Rio de Janeiro, no período de maio a junho de 2015. Os temas escolhidos como conteúdo foram educação ambiental e sustentabilidade. O projeto foi dividido em cinco etapas: 1) Diagnóstico prévio com questionário de 40 perguntas objetivas sobre os temas escolhidos; 2) Aula com conteúdo programático sobre educação ambiental e sustentabilidade; 3) Aplicação da metodologia do jogo pedagógico J3 A@; 4) Aplicação de prova sobre os temas trabalhados e 5) Avaliação dos alunos sobre da ação realizada, visando saber se a utilização do jogo pedagógico $\mathrm{J} 3 \mathrm{~A}^{\odot}$ atuou como facilitador para relembrar o conteúdo aplicado em sala de aula, se favoreceu a redução da ansiedade no momento da avaliação e se contribuiu para a melhoria da nota. O único critério de inclusão foi o participante estar regularmente matriculado nas turmas B311 $(\mathrm{n}=37)$ e B312 $(n=43)$ do primeiro ano e $\operatorname{EM} 311(n=16)$ e EM312 $(n=33)$ do terceiro ano do ensino médio do Colégio Boas Novas, RJ. Os alunos aceitaram participar da pesquisa através da assinatura do termo de consentimento livre e esclarecido.

Os temas escolhidos como conteúdo programático foram trabalhados de forma igualitária nas quatro turmas, assim como a aplicação do questionário de perguntas objetivas. Apenas para as turmas B311 e EM311 foi aplicada a metodologia do jogo pedagógico; da mesma forma, apenas para as turmas já citadas foi realizada uma avaliação para verificar se a metodologia utilizada foi eficiente para a melhoria da nota, aquisição do conteúdo e redução da ansiedade para realização de prova.

Para o jogo pedagógico, utilizaram-se a estrutura e as regras do jogo J3 A@(Registro 750347, ago/09), idealizado por um dos autores deste trabalho e implementado para método de ensino como um jogo pedagógico.

\section{Apresentação do Jogo}

O jogo, do tipo cultural, está baseado em perguntas e respostas. No início do jogo, o professor estipulou uma pontuação a ser alcançada pelos participantes. Os pontos foram se acumulando a cada rodada do jogo. Existiam quatro alternativas de resposta para cada pergunta (A, B, C, D). Para cada alternativa, foi 
inserida uma pontuação com os números 8, 4, 2 e 1, respectivamente. O professor destacou a ideia central do jogo, em que todas as posições receberam uma alternativa de resposta (sendo que a alternativa que se achasse mais correta deveria ser colocada na posição de maior valor, ou seja, com valor 8). Cada pergunta teve somente uma alternativa de resposta certa.

\section{Análises estatísticas}

Para avaliação dos dados, foi utilizado o software Statistical Package for the Social Sciences (SPSS). Para a verificação de associações no diagnóstico sobre assuntos referentes ao meio ambiente, foi utilizado o teste chi quadrado com teste posterior de Fisher's. As diferenças foram consideradas significativas quando p<0,05.

\section{Resultados}

$\mathrm{Na}$ etapa de diagnóstico, foi verificado que os alunos do $1^{\mathrm{a}}$ e do $3^{\circ}$ ano do ensino médio (EM) disseram que não tinham bom conhecimento dos termos atuais relacionados com o meio ambiente, tais como créditos de carbono $\left(75 \%, 1^{\circ} \mathrm{EM}\right.$ vs $\left.62 \%, 3^{\circ} \mathrm{EM}, \mathrm{p}=0.0342\right)$ e sustentabilidade ambiental $\left(93 \% 1^{\circ} \mathrm{EM}\right.$ vs $83 \% 3^{\circ} \mathrm{EM}, \mathrm{p}=$ 0.0427), que não tinham hábito de leitura de jornais e sites com informações sobre meio ambiente $\left(81 \% 1^{\circ}\right.$ EM vs $62 \% 3^{\circ} \mathrm{EM}$ ) e que a televisão foi a principal fonte de informação em $75 \%$ dos alunos entrevistados.

O uso da metodologia do jogo pedagógico J3 A@ mostrou-se favorável para a melhoria da nota nos temas relacionados com meio ambiente: educação ambiental e sustentabilidade, nas turmas do $1^{\circ}$ ano B311 (+47\% vs B312, $\mathrm{p}=0,0001)$ e do $3^{\circ}$ ano EM311 (+16\% vs EM312, p=0,0054) do ensino médio (tabela 1).

$\begin{array}{cccc}1^{\text {oano }} & 1^{\text {oano }} & 3^{\circ} \text { ano } & 3^{\circ} \text { ano } \\ (\mathrm{B} 312) & (\mathrm{B} 311) & (\mathrm{Em} 312) & (\mathrm{Em} 312)\end{array}$

\begin{tabular}{|c|c|c|c|c|}
\hline Número de Alunos & 37 & 43 & 16 & 33 \\
\hline Média de notas & 5,13 & 7,55 & 6,75 & 7,82 \\
\hline $\begin{array}{l}\text { Erro padrão } \\
\text { da média }\end{array}$ & 0,42 & 0,19 & 0,30 & 0,20 \\
\hline
\end{tabular}

Valor de P $\quad 0,0001^{\star} \quad 0,0054^{\star}$

$\mathrm{Na}$ etapa de avaliação na utilização da metodologia do jogo pedagógico J3 A@, $98 \%$ dos alunos do $1^{\circ}$ ano consideraram a metodologia eficiente para auxiliar a relembrar o conteúdo aplicado, enquanto que, no $3^{\circ}$ ano, esta opinião ficou em $67 \%$ dos alunos da turma. Para auxiliar na redução da ansiedade na realização da prova, $81 \%$ dos alunos do $1^{\circ}$ ano consideraram a metodologia eficiente, enquanto que, no $3^{\circ}$ ano, esta opinião ficou em $70 \%$ dos alunos da turma. Consideraram a metodologia eficiente para a melhoria da nota, $98 \%$ dos alunos do $1^{\circ}$ ano e $90 \%$ dos alunos do $3^{\circ}$ ano.

\section{Discussão}

Vive-se hoje numa sociedade que se beneficia da alta tecnologia, mas ainda apresenta dificuldades em encontrar meios que motivem os alunos na manutenção do interesse em conteúdos trabalhados em sala de aula. A utilização de recursos metodológicos diferenciados pode potencializar o desenvolvimento de diversas competências, possibilitando uma reestruturação do modo de relacionamento entre aluno professor, pois o processo de desenvolvimento atende aos vários interesses individuais e coletivos. 
Neste projeto, foi avaliada a utilização do jogo pedagógico como ferramenta dinamizadora para aquisição de conteúdos referentes ao meio ambiente: educação ambiental e sustentabilidade para os alunos do ensino médio. Escolhemos o jogo por ser uma ferramenta metodológica contrária ao modelo de ensino tradicional, pois possibilita participação ativa e a autoavaliação do processo de aprendizagem, e os temas em razão da importância que demanda da preservação do meio ambiente, indo ao encontro da necessidade de que os alunos não apenas recebam o conteúdo teórico, mas que assumam seu papel na construção de uma sociedade sustentável.

Nesse contexto, as escolas desempenham papel de fundamental importância no desenvolvimento da Educação e na ampliação da concepção prévia dos alunos a respeito dos assuntos referentes à educação ambiental, à sustentabilidade e aos graves problemas por que eles vêm passando ao longo dos anos (PEREIRA et al., 2006). É na escola que os alunos começam a familiarizar-se com conceitos científicos, que podem sensibilizar o alunado de forma mais clara e precisa, além de facilitar o diálogo com a família, o que pode possibilitar compartilhar o aprendizado dos alunos com seus familiares e amigos de forma integrada ao ambiente (VAIRO; REZENDE-FILHO, 2010). De acordo com Rodrigues et al. (2008), a educação contemporânea deve proporcionar uma ciência contextualizada capaz de contribuir para uma aprendizagem significativa, que promova a formação de cidadãos conscientes e comprometidos com a construção de uma sociedade sustentável.

Corroborando com os dados já estudados por Rodrigues (2008), pode-se verificar que os alunos do ensino médio, quando questionados sobre aspectos referentes ao meio ambiente, não possuem o hábito de buscar informações e que a televisão se apresenta como o meio de atualização mais citado. Também observamos que os alunos entrevistados não acessam sites com informações sobre meio ambiente. Portanto, é válida a preocupação que se tem atualmente com o tempo gasto por crianças e jovens diante da televisão ou com o celular, porém sem buscar uma informação com conteúdo formativo.

Assim sendo, os alunos do $1^{\circ}$ e do $3^{\circ}$ ano do ensino médio tiveram dificuldades em conceituar créditos de carbono e sustentabilidade ambiental. Muito provavelmente o tempo e atenção disponibilizados para estes temas, unidos à falta de informação, contribuíram para a apresentação destes dados. Créditos de carbono e sustentabilidade ambiental são temas atuais e vinculados a um comprometimento com o desenvolvimento sustentável. Segundo Saquetta, Balbinot e Zilioto (2004), foram estabelecidas metas de redução de gases de efeito estufa no protocolo de Kyoto no Japão, visando contribuir para a redução do aquecimento global e a criação de um sistema de negociação de unidade de redução (URE), utilizado por diversas empresas mundiais.

As médias das notas foram maiores nas turmas onde foi trabalhado o jogo pedagógico, mostrando que o uso de uma metodologia mais motivadora pode ser favorável à aquisição do conteúdo de forma mais atraente e dinâmica e que, muito provavelmente, a atenção do aluno fique mais retida em relação ao que acontece em sala de aula. Diversos trabalhos realizados mostram a necessidade no desenvolvimento de estratégias que favoreçam o desenvolvimento do trabalho pedagógico de forma mais proveitosa para os alunos e para a realização pessoal no trabalho de docência (KISHIMOTO, 2001; PEREIRA; SOUZA, 2004; SILVA; AZEVEDO, 2005).

Atualmente, os jovens estão envolvidos numa atmosfera mais rápida e dinâmica, porém consomem o tempo disponível, na maioria das vezes, em jogos não pedagógicos, em sites de relacionamento e em diálogos rápidos na rede. É necessário canalizar as potencialidades das novas gerações para a educação e para a capacitação profissional. Para este objetivo, o ambiente da escola precisa ser mais dinâmico, buscando aproveitar o que se tem de melhor nos alunos para que eles mesmos possam, naturalmente, canalizar suas qualidades diversas para a formação pessoal e profissional. Talvez se possa extrair o melhor de nossos alunos através do uso de metodologias que estejam em sintonia com a visão de realidade que eles possuem.

Nas avaliações sobre a percepção dos alunos do ensino médio sobre a atividade realizada, foi possível verificar que o uso de metodologias mais dinâmicas pode auxiliar na aquisição do conteúdo, na redução da ansiedade diante de um processo de avaliação e na melhoria da nota. Nossos dados corroboram com os de Kishimoto (2001), que descreve que a utilização do jogo em sala de aula não é uma finalização, mas sim uma ponte que conduz ao conteúdo didático específico e resulta no empréstimo da ação lúdica na aquisição de informações. 
Kishimoto (2001) em sua obra Jogo, Brinquedo, Brincadeira e a Educação apresenta o uso do brinquedo e do jogo educativo com fins pedagógicos, nos remetendo à relevância desse instrumento para situações de ensino -aprendizagem e de desenvolvimento infantil, trabalhando o cognitivo, afetivo, físico e social da criança.

Assim sendo, podemos concluir que o uso da metodologia de jogo pedagógico mostrou-se uma estratégia de ensino-aprendizagem motivadora para a melhora na aquisição do conteúdo trabalhado em sala de aula, contribuindo com a consciência ecológica nos sujeitos sociais, utilizando-se da educação para desenvolver uma perspectiva modificadora da realidade.

\section{Contato dos autores}

Christiane Leal Corrêa | christiane.leal@gmail.com

\section{Referências Bibliográficas}

KERFOOT B. P.; BAKER H. An online spaced-education game to teach and assess residents: a multi-institutional prospective trial. J Am Coll Surg, Boston, 214(3):367-73, 2012.

KISHIMOTO, M. T. Jogo, brinquedo, brincadeira e a educação. 5. ed. São Paulo: Cortez, 2001.

LIMA, K. C.; VASCONCELOS, S. D. Análise da metodologia de ensino de ciências nas escolas da rede municipal de Recife. In: Ensaio: avaliação e políticas públicas em educação, vol.14, n.52, pp. 397-412, 2006.

MENEGHETI, M.; BUENO, C.; BITTAR, M. L. Ação e aprendizagem: o teatro como facilitador da socialização na escola. In: Fractal, Rev. Psicol. [online]. vol. 22, n.1, pp.187-204, 2010.

PEREIRA, L. C.; SOUZA, N. A. Concepção e prática de avaliação: um confronto necessário no ensino médio. Estudos em Avaliação Educacional. In: Revista da Fundação Carlos Chagas, São Paulo, v. 29, p. 191-208, 2004.

PEREIRA, E. M.; FARRAPEIRA, C. M. R.; PINTO, S. D. L. Percepção e educação ambiental sobre manguezais em escolas públicas da região metropolitana do Recife. in: Revista Eletrônica do mestrado em Educação Ambiental, v. 17, p. 244-261, 2006.

RODRIGUES, L. L.; FARRAPEIRA, C. M. R.; LOPES-RODRIGUES, R. O. Percepção e educação ambiental sobre ecossistema manguezal incrementando as disciplinas de ciências e biologia em escolas públicas do Recife-PE. In: Investigações em Ensino de Ciências, v. 13, n. 1, p. 79-93, 2008.

SAQUETTA, C. R.; BALBINOT, R.; ZILIOTO, M. A. Fixação do carbono: atualidades, projetos e pesquisas. Curitiba, 2004.

SILVA, C. M. T.; AZEVEDO, N. S. N. O significado das tecnologias de informação para educadores. In: Ensaio: avaliação e políticas públicas em educação, v. 13, n. 46, p. 39-54, 2005.

VAIRO, A. C.; REZENDE-FILHO, L. A. Concepções de alunos do ensino médio sobre ecossistemas de manguezal: o caso de um colégio público do Rio de Janeiro. In: Revista Eletrônica do Mestrado Profissional em Ensino de Ciências da Saúde e do Ambiente, v. 3, n. 2, p. 15-25, 2010. 